\title{
The Application of the Prototype Theory in Lexicographic Practice: A Proposal of a Model for Lexicographic Treatment of Polysemy*
}

\author{
Ana Halas, Faculty of Philosophy, University of Novi Sad,
} NoviSad, Serbia(anahalas@gmail.com)

\begin{abstract}
The aim of this paper is to point to fundamental implications of the prototype theory for lexicographic practice using them as a solid foundation for developing and proposing a model for systematic, consistent, precise and, above all, reliable treatment of polysemy in dictionaries. The main requirement of such a model is to make transparent the main features of a polysemous structure including its hierarchical organization, mutual relatedness of senses based on family resemblance and motivated derivation of senses. The proposed model includes three most challenging but key aspects of lexicographic treatment of polysemy: sense discrimination, sense defining and structure and organization of a dictionary entry. The prototype-based view of a polysemous structure is illustrated with a diagram representing a proposed upgrade of the radial set model introduced by Brugman and Lakoff (1988) and providing a pattern for tailoring a dictionary entry for a polysemous word. After practical aspects of the proposed model are explained in detail, an illustration follows setting forth a sample entry for a highly polysemous verb formed according to the proposed model. A solid theoretical foundation of the model is expected to ensure its practical efficiency primarily concerning quick and easy detection and understanding of senses.
\end{abstract}

Keywords: LEXICOLOGY, LEXICOGRAPHY, COGNITIVE LINGUISTICS, PROTOTYPE THEORY, POLYSEMY, DICTIONARY ENTRY, MODEL, SENSE DISCRIMINATION, SENSE DEFINING, ENTRY STRUCTURE

Opsomming: Die toepassing van die prototipeteorie in die leksikografiese praktyk: 'n Voorstel vir 'n model vir die leksikografiese hantering van polisemie. Die doel van hierdie artikel is die aantoon van basiese implikasies van die prototipeteorie vir die leksikografiese praktyk en die gebruik daarvan as stewige grondslag vir die ontwikkeling en voorstelling van ' $n$ model vir sistematiese, konsekwente, noukeurige en veral betroubare hantering van polisemie in woordeboeke. Die belangrikste vereiste vir so 'n model is die verheldering van die hoofkenmerke van 'n polisemiese struktuur met inbegrip van hiërargiese samestelling, onderlinge verwantskap van betekenisse gegrond op gemeenskaplike ooreenkomste en gemoti-

* This paper is based on the author's doctoral dissertation written under the supervision of Professor Tvrtko Prćić and defended at the University of Novi Sad. 
veerde afleiding van betekenisse. Die voorgestelde model sluit drie uiters uitdagende maar sleutelaspekte van die leksikografiese hantering van polisemie in: betenisonderskeiding, betekenisdefiniëring en die struktuur en samestelling van 'n woordeboekinskrywing. Die prototipe-gebaseerde beskouing van ' $n$ polisemiese struktuur word geïllustreer deur ' $n$ diagram. Hierdie diagram is 'n voorgestelde verbetering van die radiale reeks-model wat deur Brugman en Lakoff (1988) bekendgestel is en wat 'n ontwerp verskaf vir die skep van 'n woordeboekinskrywing vir 'n polisemiese woord. Nadat die praktiese aspekte van die voorgestelde model in besonderhede uitgelê is, volg daar 'n illustrasie van 'n voorbeeldinskrywing vir 'n hoogs polisemiese werkwoord wat geskep is volgens die voorgestelde model. Daar word verwag dat 'n stewige teoretiese grondslag vir die model die praktiese doeltreffendheid daarvan, veral betreffende die vinnige en eenvoudige vasstelling en begrip van die betekenisse, sal verseker.

Sleutelwoorde: LEKSIKOLOGIE, LEKSIKOGRAFIE, KOGNITIEWE LINGUISTIEK, PROTOTIPETEORIE, POLISEMIE, WOORDEBOEKINSKRYWING, MODEL, BETEKENISONDERSKEIDING, BETEKENISDEFINIËRING, INSKRYWINGSTRUKTUUR

\section{Introduction}

The advent of cognitive linguistics in the 1980s marked a turning point in the development of semantic theories and their view of meaning bringing the notion of polysemy into focus again. One of the main advances in the perception and understanding of polysemy within the framework of cognitive linguistics was the incorporation of the prototype theory into its account of word meaning. The prototype theory represented a strong and direct opposition to the classical view of words and their meaning relying on psychology and its empirical findings, viewing meaning as a form of categorization and relating it to mental representations. Such an account of meaning and polysemy is considered here as the one that can be successfully applied to lexicographic treatment of polysemy. However, the analysis of polysemy treatment in British and American lexicography (represented by six monolingual general-purpose dictionaries and five learner's dictionaries of English) that I have conducted as a part of my doctoral dissertation (Halas 2014a) has shown that most of these dictionaries still adhere to the principles of traditional lexicography and do not base their practice on contemporary lexicological theory. The New Oxford Dictionary of English (NODE, Pearsall 1998) is the first dictionary to be compiled taking into account achievements of cognitive semantics so that its main characteristic is the differentiation between a lexeme's main uses labelled as core senses and their subsenses, i.e. more specific uses (Halas 2014b: 160) as well as the organization of senses within entries that shows that they "hang together" (Van der Meer 2000: 421) and that they are not mutually independent. However, after analysis of this dictionary's practice, Van der Meer (2000: 428) concludes that it is not completely coherent and consistent in applying the principles of the given theoretical basis.

The main premise in this paper is that complete fulfilment of users' needs 
results from a successful interplay of the contemporary lexicological theory and lexicographic practice. Furthermore, the prototype theory has been recognized in this paper as highly beneficial to lexicographic treatment of polysemy including all its most challenging aspects - sense discrimination, sense defining and structure of the entry. Therefore, this paper presents an attempt to clearly point to the ways in which the application of the prototype theory can increase efficiency and user-friendliness of lexicographic practice concerning the treatment of polysemy as well as reliability of data presented in a dictionary entry. Thus, there will be formulated a proposal of a model for lexicographic treatment of polysemy completely based on the principles of the prototype theory.

\section{The prototype-based view of polysemy}

The notion of polysemy is typically associated with a multiplicity of senses of a single lexeme. However, the key feature of polysemy that differentiates it from other cases of lexical ambiguity, such as homonymy, is defined by Cruse (2004: 108) as a motivated relationship between senses. This relationship is motivated since each sense is derived from another one in the same polysemous structure through a mechanism of sense extension, such as: specialization, generalization, metaphor, metonymy, etc. This mutual relatedness of senses within a polysemous structure became especially prominent when the cognitive linguistic view of polysemy arose. Thus, when defining polysemy, Evans (2005: 33) also emphasizes that polysemy is a phenomenon "whereby a single linguistic form is paired with a number of distinct but related meanings or senses".

Cognitive linguistics has studied polysemy as a form of categorization (Lewandowska-Tomaszczyk 2007: 140). Wittgenstein (1980) defined categorization as speakers' ability to perceive entities as members of particular groups or categories, while each category has its own typical features. Wittgenstein also concludes that categories have blurred boundaries while their members are related on the basis of family resemblance since their common features "overlap and criss-cross" just like traits in one family (Ravin and Leacock 2006: 13).

On the basis of the results of her psychological experiments, Rosch (1977) reaches the conclusion that people categorize entities on the basis of their resemblance to the best exemplar of the given category that exhibits the most salient features of the category. The central member of a category is the prototype, the best representative of the given category. The other members of the category exhibit different degrees of their similarity with the prototype. For example, if the category of birds is taken into consideration, a sparrow could be regarded as the prototypical bird, i.e. the prototype of the category of birds. A pigeon, swallow or canary exhibit a greater degree of similarity with the prototype due to which, in a visual representation of this category, they should be positioned closer to the center, while a penguin or a platypus share a smaller number of features with the prototype so that they are regarded as peripheral members (Prćić 2016: 59). Therefore, some members are better exemplars of the 
category, while others are less representative, which leads to the conclusion that the category membership is graded. Hence, the internal structure of a category develops from its core, i.e. the prototype and extends gradually over the central members as more typical ones to peripheral, less typical members. Actually, the main criterion for determining the position of an individual member in a category can be regarded as goodness-of-exemplar (Croft and Cruse 2004: 77).

The key aspects of the prototype-based view of categories can be summarized in four prototypicality effects or features formulated by Geeraerts (1989):

(1) Prototypical categories exhibit degrees of typicality.

(2) Prototypical categories are blurred at the edges.

(3) Prototypical categories cannot be defined by a single set of (necessary and sufficient) features.

(4) Prototypical categories exhibit a family resemblance structure.

Since polysemy is viewed as a form of categorization within the cognitive linguistic theoretical framework, the four prototypicality features apply to a polysemous structure as well. Interpreted in the specific context of polysemy, the first feature refers to the difference among senses in their structural weight due to the fact that there is a prototypical sense lying at the core of the structure while the other senses can be more or less central or peripheral depending on the number of features, or in this particular case - sense components, they share with the prototype. The second prototype effect indicates the flexibility of prototypical categories, which means that, as Taylor (1989: 53) claims, they can include new members without any restructuring of the whole category. In the case of a polysemous structure, these new members refer to newly derived senses since a polysemous structure can be enriched and expanded through meaning extension. A polysemous structure is also defined in terms of a cluster of partial descriptions since none of the members of a particular category exhibits all of its typical features, i.e. none of the senses in a polysemous structure possesses all the prototypical components. Hence, there is not a single set of features typical of a particular category common as a whole to all of its members. Thus, Lewandowska-Tomaszczyk (2007: 146) explains that there is not a set of necessary and sufficient features by which a category can be defined but rather categories are defined in terms of a cluster of partial descriptions. Still, all the senses within a single polysemous structure are organized around and derived directly or indirectly from the same prototype so that they are all mutually related sharing some common features and overlapping, which indicates that mutual relatedness of senses within a polysemous structure is based on family resemblance.

Lakoff (1987) sets forth his view that polysemous words should be understood as radial categories. Brugman and Lakoff (1988) present the radial set model for the description of a polysemous structure. According to this model, the central member, i.e. the prototype is a cognitive model that motivates all 
the other senses in the given structure and they are all positioned relative to the center. The visual representation of Lakoff's radial set model is given below:

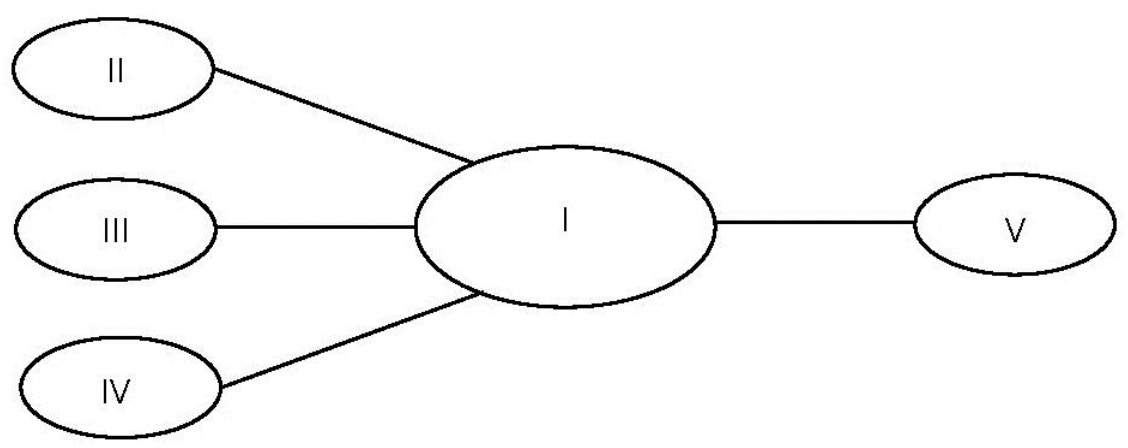

Figure 1: A radial set (Lewandowska-Tomaszczyk 2007: 156)

Evans (2005: 34) follows Lakoff's model and, thus, arrives at a similar description of a polysemous structure claiming that all senses in one such structure form a motivated semantic network organized around a central sense that this author refers to as the sanctioning one. Senses in a polysemous structure are linked to the prototype through various mechanisms (e.g. metaphor, metonymy, etc.) by means of which they are derived from it. As Evans and Green (2006: 332) explain, the operation of these mechanisms results in the formation of meaning chains creating a polysemous structure of a lexeme. As the main advantage of the radial set model, Evans (2005: 40) emphasizes the fact that it clearly shows degrees of relatedness between senses since some senses are more closely related to the prototype while others can be more closely related to some derived sense in the structure. The afore-mentioned author sees this as clustering of senses according to patterns that reveal possible paths of derivation. Actually, senses in a structure are mutually connected by relational links representing pathways along which one sense has been derived from another. As Geeraerts (2001: 11) notices, the radial set model emphasizes the multidimensional nature of a polysemous structure arising from mutual derivational links among senses.

\subsection{The upgrade of the radial set model by Brugman and Lakoff}

The prototype-based model offers a deeper insight into the internal organization of a polysemous structure focusing upon its center as the core from which the whole structure has developed and, thus, emphasizing mutual relatedness of all the senses in a structure based on family resemblance, which is successfully visually represented by the radial set model introduced by Brugman and Lakoff (1988). However, the fact that should not be neglected is that the proto- 
type-based model of polysemy also emphasizes that there are differences among senses in their structural weight and centrality. Basically, the organization of a polysemous structure follows the cline from center to periphery (Geeraerts 2001: 11). Moreover, noticed differences in structural weight and centrality among senses strongly suggest that a polysemous structure is hierarchically organized, which provides the basis for proposing an upgrade of the radial set model that will present the internal structure and organization of a polysemous structure in even greater detail.

The visual representation of this model consists of a set of concentric circles where each circle represents a level of semantic derivation. The basic or prototypical sense of the given polysemous structure is positioned in the center of the diagram, which is in accordance with its primary and central status in the structure, as can be seen in the illustration of the model shown below.

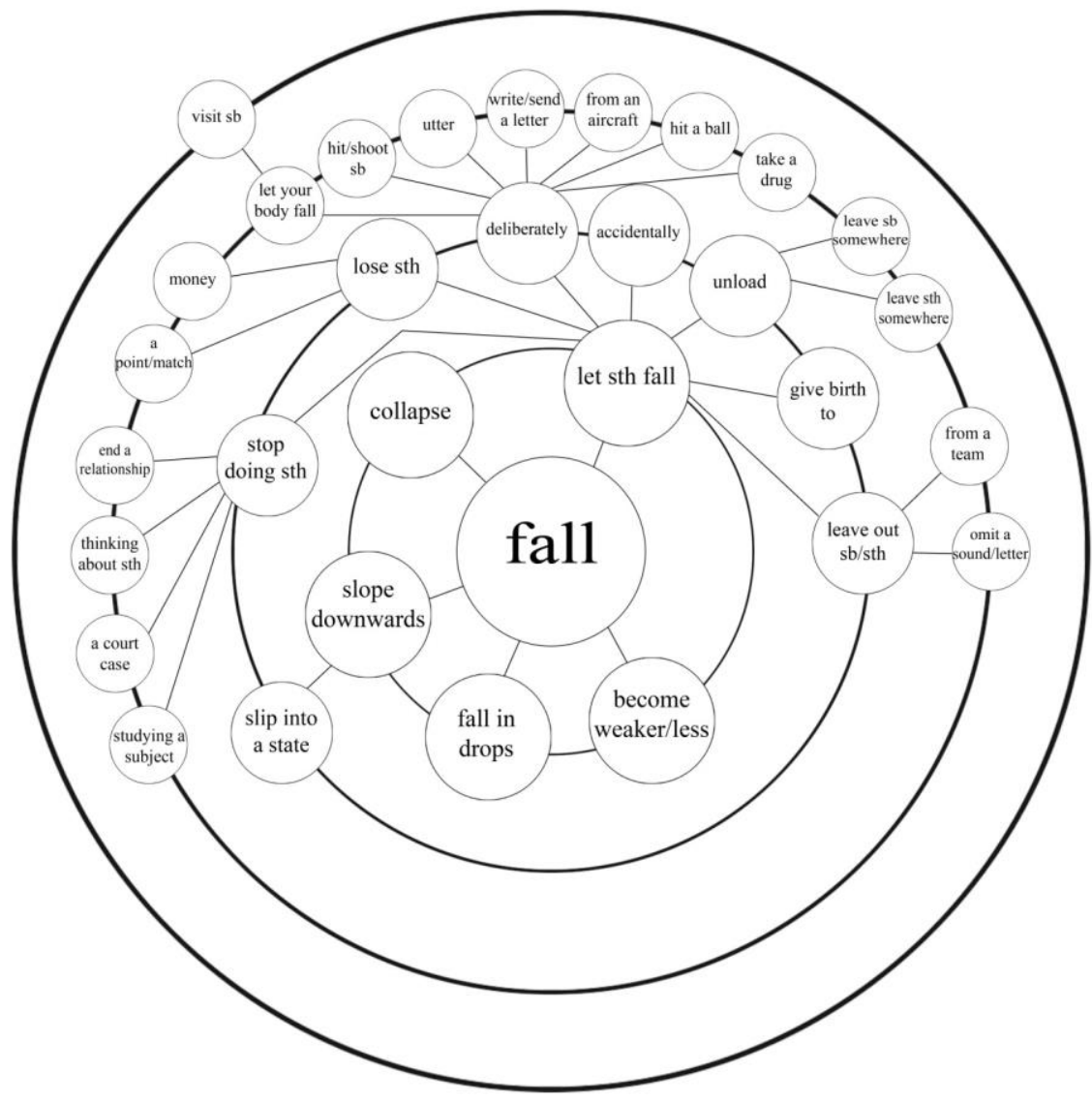

Figure 2: The polysemous structure of the verb drop according to the proposed upgrade of the radial set model 
This is a diagram reflecting the highly polysemous structure of the verb drop, including a considerable number of senses so that as such it is an illustrative example of the way in which this model actually functions. The prototypical sense of this verb is 'fall'. The question that arises here is how the prototypical sense is established. Evans (2005: 44) proposes four criteria for determining the prototypical sense of a polysemous structure: 1) historically earliest attested meaning, 2) predominance in the semantic network in the sense of typefrequency, 3) predictability regarding other senses, 4) a sense which relates to lived human experience, i.e. experience at the phenomenological level. Since the model proposed in this paper is based on the view that a polysemous structure is characterized by family resemblance while representing a motivated network of senses, the criterion applied for the identification of the prototypical sense presents the interplay of the second and third listed criteria. The second criterion suggests that the prototype should be determined on the basis of the meaning component that is the most frequent in the given structure. The third criterion is in accordance with Evans' claim that sense derivation is principled and motivated so that the prototype is the sense from which the other senses "most naturally" have been derived (Evans 2005: 44). Hence, the prototype is established as the sense component that is directly or indirectly incorporated into the other senses in the given structure representing the core from which, most plausibly, they have been derived directly or indirectly.

The center of the diagram is surrounded by a certain number of evenly spaced concentric circles. In the case of the polysemous structure of the verb drop, there are four concentric circles since the given structure encompasses four levels of semantic derivation. Thus the number of concentric circles surrounding the center of the diagram is actually dictated by the complexity of the polysemous structure in question, i.e. by the number of its derivational levels. The first concentric cycle or level of semantic derivation (the one closest to the center) contains senses directly derived from the prototypical one. They will be referred to as primary senses. In this particular case, there are five primary senses derived from the prototypical sense through various mechanisms: metaphor ('become weaker/less'), metonymy ('let something fall'), and specification ('fall in drops', 'slope downwards', 'collapse'). These primary senses can have their own potential for further semantic dispersion and act as the basis for the derivation of other, new, more peripheral senses less closely related to the prototype. These senses indirectly derived from the prototype will be referred to as secondary senses and they are positioned on the second derivational level (i.e. the second concentric circle). Two of the five identified primary senses of the verb drop are semantically productive in the sense that they have a semantic potential for derivation of new senses. One of them is the sense 'let something fall' that is the base from which several secondary senses have been derived through metaphor ('stop doing something', 'lose something', 'unload', 'give birth to', 'leave somebody out') and specialization ('let something fall deliberately', 'let something fall accidentally'). The mentioned primary sense acts, thus, 
as the superordinate to its subsenses, i.e. the mentioned more peripheral senses directly derived from it and only indirectly from the prototype. Hence, the relation of subordination is established between most closely related senses, i.e. the superordinate sense and its subsenses. This fact proves the existence of a hierarchy within a polysemous structure. Moreover, derivational paths for all senses descending from the first to the second derivational level, i.e. from superordinate senses to their subsenses become transparent in this model. However, the sense derivation process is a recurrent one, which means that every secondary sense from the second derivational level can also be the base for further sense derivation and become the superordinate sense to the senses derived from it directly, i.e. to its subsenses positioned on the next, third level being even more peripheral so that the same relation of subordination and hierarchy is established between the senses on the second level and the corresponding derived senses on the third level. An illustrative example is the sense 'let something fall deliberately' from which a number of more peripheral senses have been derived as it can be seen on the diagram. The senses on the third level can also become derivational bases motivating further semantic dispersion. Hence, this recurrent nature of the process of semantic derivation ensures further extension of a polysemous structure.

\section{The implications of the upgraded prototype-based model for the lexicographic treatment of polysemy}

As Atkins and Rundell (2008: 130) claim, a grounding in relevant theoretical ideas or those that have direct application to lexicographers' work is an invaluable tool when tackling the task of analyzing data and tailoring precise and neat dictionary entries. It is considered here that only lexicographic practice with a solid foundation in the contemporary lexicological theory can provide a valid and credible description of a semantic structure within a dictionary entry. As it has been concluded that the prototype theory provides an insight into the internal organization of a polysemous structure, it can be used as a firm and, above all, useful theoretical basis for the lexicographic treatment of polysemy. The proposed upgraded model of representing a polysemous structure makes this insight even deeper and more detailed on the basis of which it is possible to analyze the semantic structure of the given entry. When the given semantic structure is analyzed and represented according to this model, lexicographers have a clear and detailed depiction of this structure that serves as a pattern for tailoring a dictionary entry for the given lexeme taking into account all the key aspects of polysemy treatment: sense discrimination, sense definition and structure and organization of senses within an entry. In this way, this challenging and particularly important aspect of lexicographic practice ceases to be arbitrary, random and subjective and becomes systematic, theoretically wellfounded but also practically efficient, which will be proved in the following sections of the paper. 
The fundamental implications of the proposed upgraded prototype-based model of representing a polysemous structure for the lexicographic treatment of polysemy are set forth below:

(1) A polysemous structure is organized around the prototype as the motivational core from which all the other senses in a structure are derived directly or indirectly. Therefore, when establishing the semantic structure of a polysemous lexeme, lexicographers' initial step is to identify the prototype as the basic sense in the given structure.

(2) Derivation of senses within a polysemous structure is motivated. As it has already been explained, a new sense is derived from another one in the structure through the activation of a sense derivation mechanism. This clearly suggests, as Csábi (2002: 250) points out, that lexicographers should do the motivational analysis of senses, which includes identifying a derivational path for each sense as well as recognizing the activated mechanism. In this way, there are established groups of closely related senses comprised of a superordinate sense and its subsenses.

(3) Mutual relatedness of senses based on family resemblance naturally stems from previously explained motivated sense derivation. Motivated derivational links existing between a superordinate sense and its subsenses as well as the fact that all senses in a structure originate directly or indirectly from the same prototypical sense strongly imply that one sense cannot be defined as an independent, individual use of the given lexeme but as relative to its closely related senses. Accordingly, in order to provide a complete and reliable description of a sense, definitions should reflect these family resemblances as well as the hierarchy of a polysemous structure.

(4) Due to the organization according to the principle 'from center to periphery' and the relation of subordination between a superordinate sense and its subsenses, it follows that only a hierarchically structured dictionary entry does full justice to the multilayer internal organization of a polysemous structure.

These implications are underpinning theoretical principles of the proposed model for the lexicographic treatment of polysemy. Practical aspects of this model, an illustration of its application and its advantages will be presented in the following sections of the paper.

\section{Practical aspects of the proposed model for lexicographic treatment of polysemy}

Practical aspects of the proposed lexicographic model will be explained through reference to three key aspects of polysemy treatment: sense discrimination, sense defining and structure and organization of an entry. 


\subsection{Sense discrimination}

Sense discrimination is in this paper understood as a lexicographic procedure including sense identification and sense differentiation. Sense identification subsumes two tasks: identification of the basic/prototypical sense and identification of other senses in a structure, both primary and secondary ones. After a thorough search of a corpus and gathering all possible uses that form the semantic network of the given lexeme, a lexicographer should identify its semantic core, i.e. the semantic base from which all the other members of the given structure have been derived directly or indirectly (Halas 2014b: 161-162). The analysis of the semantic network of the verb drop ${ }^{1}$ clearly shows that the most plausible and natural semantic core of the polysemous network of the verb drop is the sense 'fall vertically'.

Identification of other senses in a structure, both primary and secondary ones, consistently follows detected sense derivation paths descending from a superordinate sense to its subsenses. For each specific use of a particular lexeme, a lexicographer should identify the sense which it has been derived from, i.e. its superordinate as well as a mechanism of its derivation. Subsequently, the semantic potential of the given use is to be analysed with the purpose of identifying all its subsenses. It follows from this that it is necessary to establish each derivational path in its entirety descending from the first to the last derivational level in a structure. Thus, the hierarchical relation among senses in a structure is another principle that governs the sense identification process according to this model. An example of a derivational path within the polysemous structure of the verb drop is the following: the primary sense 'let something fall' is derived directly from the prototypical sense 'fall vertically' through the mechanism of metonymy (according to the pattern MOVE ON ITS OWN (OF AN OBJECT)-MAKE IT MOVE) but it also acts as a superordinate sense from which several secondary senses have been derived, such as the sense 'stop doing something' (through metaphor according to the pattern DISCONTINUING SOMETHING IS LETTING IT FALL) positioned accordingly on the second derivational level. However, this derivational path reaches up to the next, third derivational level since there are several specific uses of the verb drop that are identified as subsenses of the mentioned secondary sense, such as: 'end a relationship', 'stop studying a subject' (derived by means of specialization realized by specifying a referent, e.g. a relationship, a school subject), etc. The analysis of their derivational origin leads to the sense 'stop doing something' as their derivational base. Generally, the initial step in the sense identification process is to recognize the specific nature of a particular use in the corpus, which is followed by the reconstruction of its derivational path through gaining an insight into its relation to the other senses in the structure.

When a specific use of the given lexeme is identified and established, the questions that arise are firstly, whether it is possible and secondly, whether it is needed to decompose the given use into several more specific, more narrowly 
defined senses. This is the task of sense differentiation that is to be in accordance with the hierarchical organization of a polysemous structure so that its procedure is based on a proper combination of lumping and splitting of senses. This means that superordinate senses should be identified as more general uses while their subsenses should be finely differentiated one from another so that subtle distinctions among them are visible and prominent enough especially if their specific features are semantically productive and, thus, significant for further sense derivation. The described procedure is exemplified by the use 'let something fall' that is established as a quite broad superordinate sense whose wide range can encompass various more specific uses as its subsenses. On the second derivational level, there are two recognized variations of this general sense involving different ways of letting something fall denoted by its subsenses 'let something fall deliberately' and 'let something fall accidentally'. It is completely justified to split the mentioned more general superordinate sense into these two subsenses and establish them as individual senses since the distinction between them reflected in the opposition of sense components 'deliberately-accidentally' is of essential importance for further sense derivation. Namely, several new senses are identified as derived from the sense 'let something fall deliberately' which is obviously highly semantically productive as it can be seen in the figure 2 . Therefore, differentiae among the subsenses on the third derivational level should be elicited in order to make these specific senses prominent enough.

However, as Stock (1984: 131) underlines, it is of crucial importance to establish the adequate extent of splitting more general senses into very subtle nuances of meaning which become individuated in this way although there are rather slight differences among them. Therefore, there is a risk of making such differentiation redundant and unnecessarily detailed. This can lead to a too great number of subsenses, which requires too much effort from a lexicographer to organize them into a neat and clear list of senses as well as for a user to easily and quickly spot the desired sense. For example, the subsense 'to let a part of your body fall suddenly' could be further split into at least three subsenses by eliciting differences among them that refer to the exact part of the body which is dropped (e.g. mouth, jaw, eyes). However, this difference is not of relevance for further semantic derivation and individuation of each of these variations would only unnecessarily increase the number of individual senses and make the organization of the entry too complex and detailed, thus, harming its transparency. It is not advisable either to entirely neglect these variations of the given more general sense or miss to make them visible. An optimal solution in such cases could be to specify these various referents in sentences or phrases serving as illustrative examples following and supporting the definition of the mentioned sense. The same practice can be applied to the primary sense 'become weaker, less, lower' that can be split into several individual subsenses on the basis of various referents it is used with, such as voice, wind and speed. However, a more practically efficient solution would be to lump these 
possible variations into a single individual sense and specify them in illustrative examples so that this certainly would not harm the preciseness of representing the sense inventory of the verb drop. The recommended practice will be illustrated in the proposed dictionary entry for the verb drop that will be presented in the following chapter of the paper.

In conclusion, it can be stated that, according to the proposed theoretical model, sense differentiation is to follow the systematic combination and balancing of sense lumping and splitting following the rule which states that superordinate senses tend to be generalized, while their subsenses should be established through splitting and subtle sense differentiation especially if the established differentia is significant for further semantic dispersion and if it contributes to the necessary preciseness of representing the sense inventory without harming its clarity and neatness.

\subsection{Sense defining}

According to the proposed model, the crucial requirement that sense definitions are expected to fulfil is to reflect motivated nature of sense derivation. This basically indicates that mutual relatedness of senses within a polysemous structure based on family resemblance is to be made transparent with a proper formulation of sense definitions. In order to make this relatedness among senses easily noticeable, it is necessary to provide a formal indication of this relation in the very sense definitions of every superordinate sense and its subsenses. That formal indication is the identical formulation of the common semantic base or the common dominant feature shared between a superordinate sense and a sense directly derived from it, i.e. the feature that motivated the given sense derivation. This also implies that the formulation of each sense definition should be such that every derived sense can be easily related to its superordinate sense and that its derivational path including the employed derivational mechanism is transparent. Thus, the formulation of the common semantic core shared by the prototypical sense of the verb drop and all the primary senses directly derived from it is 'to fall vertically' and the identical formulation of this core is contained in the definitions of all the primary senses. In this way, it becomes obvious that they are related to the prototypical sense. Consequently, it also becomes obvious that these senses are all mutually related due to their common derivational origin and family resemblance. The same principle applies to defining of secondary senses.

Thus, according to the proposed model, the formulation of sense definitions adopts the following procedure: the basis of a sense definition is established by excerpting the formulation of the common dominant component or semantic core from the definition of its superordinate sense (i.e. from the definition of the sense it has been derived from) so that the identical formulation of the shared basic component is present in the definitions of the two most closely related senses. Then, the explanation of the component(s) specific for the sense 
being defined is added to the formulation of the shared basic component. The explained procedure is illustrated by definitions of senses belonging to the same derivational path descending from the prototype to the second derivational level. The definition of the primary sense 'to make something fall vertically' contains the component on the basis of which it has been derived from the prototype which is 'to fall vertically'. The text of the given definition further incorporates the component specific for this primary sense that reflects the metonymic pattern motivating this derivation, (MOVE ON ITS OWN (OF AN OBJECT)-MAKE IT MOVE), so that the final formulation of this definition as a whole is: 'to make something fall vertically'. This primary sense has a considerable semantic potential since a number of new senses have been derived from it as it has already been noticed. One of its subsenses or senses from the second derivational level is 'to deliberately make something fall vertically'. Its definition has obviously been formulated in the following way: the dominant component it shares with the superordinate sense has been incorporated into the definition using the same formulation. Then, its specific semantic component, 'deliberately', has been added. In this way, the relation between this subsense and its superordinate sense has been made explicit and transparent while its narrower scope and more specific nature have been pointed out as well. Moreover, the hierarchical relation between the superordinate sense and its subsense has been reflected by their definitions since the superordinate sense is defined more broadly so that its scope encompasses all its more specific subsenses.

One can put the question about the application of this model to the case of defining metaphorical senses whose link with their superordinate is not obvious to the same extent as in the previous case since it is reflected in the metaphoric pattern according to which the given metaphorical sense has been derived. The model of defining metaphorical senses will be exemplified by the sense 'to stop doing something'. It has been derived from the sense 'to make something fall vertically' through the metaphorical pattern STOPPING DOING SOMETHING IS MAKING AN OBJECT FALL TO THE GROUND. Atkins and Rundell (2008: 287) claim that figurative extension of meaning (or the derivation of metaphorical senses) involves an implied resemblance between the literal and newly derived non-literal sense. In this particular example, the derivation of the new sense is based on the similarity with the component of the literal sense referring to the act of making something reach an endpoint, which, in this case, is the point at which an object reaches the ground. In the given metaphorical sense, the endpoint is the one at which one stops performing some activity. This metaphorical pattern is to be made explicit in the sense definition so that the derivational link between the metaphorical sense and its superordinate sense becomes transparent. This can be achieved by incorporating the metaphorical pattern into the formulation of the definition in the following way: 'to stop doing something (which resembles making an object fall to the ground)'.

Svensén (2009: 224-225) states that it is not always possible to determine a set of necessary and sufficient distinctive features to be included into a sense 
definition since borderlines of categories are fuzzy so that a lexicographer might choose to define such a phenomenon by describing the typical case often introducing it by words such as typically, usually, especially, often or by listing typical exponents of a category preceded by expressions like for example, e.g., such as etc. Jackson (2002: 95) refers to such definitions as 'typifying' ones. Similar definitional practice is applied in the model proposed in this paper and it can be illustrated by the following definitions: 'to stop having a relationship with someone, especially a romantic one' or '(of an animal) to give birth to young, especially a foal (which resembles making an object fall to the ground)'. In these prototype-based definitions, the typical case is clearly pointed out by the expression especially. Jehle (2004: 58 ) underlines that pointing to typical subjects and circumstances of a verbal activity in sense definitions helps users to understand but also create idiomatic sentences in the given language by thinking of referents that are matched against typical ones on the basis of family resemblance.

Therefore, the system of sense definitions within one entry established in the previously explained manner contributes largely to the reliable representation of a polysemous structure as a unified whole based on family resemblance.

\subsection{Structure and organization of entries}

According to the proposed model, the entry is structured hierarchically since it is claimed here that this type of structure can most reliably depict the multilevel nature of a polysemous structure. An entry can have a two, three or even four-layer hierarchical structure. Each entry is divided into as many numbered paragraphs as there are identified primary senses in the given polysemous structure. However, there is one paragraph at the very head of the list of senses clearly separated from the others and underlined. This is the paragraph for the prototypical sense of the given polysemous structure marked by number one so that its central position and status in a polysemous structure is clearly indicated. Every next paragraph in the list of senses encompasses a group of most closely related senses, i.e. the superordinate sense and all its subsenses or one entire derivational path descending from the first to the last derivational level in the structure. The most prominent element in one such paragraph is the primary sense acting as the superordinate one and it is always numbered. Its direct subsenses are listed immediately after it and are marked by letters following the model a,b,c, etc. Each of these subsenses is presented within a separate subparagraph slightly indented in relation to the paragraph of its superordinate sense forming, thus, the second hierarchical layer in the entry. If some of the subsenses from the second derivational level act as the bases for further semantic derivation, it is necessary to form the third layer in the structure. Actually, a subsense marked by a letter that has such a semantic potential becomes secondarily superordinate to its direct subsenses each of which is positioned within its own sub-subparagraph slightly indented in relation to the 
paragraph of its superordinate sense and it is marked according to the following model: a.1,a.2,a.3; b.1,b.2,b.3 etc. New or deeper layers in the hierarchical structure of the entry are formed using the same model and are marked in the following way: a1.1, a1.2, a1.3, etc.

Such a detailed and precise hierarchical structure of an entry effectively contributes to the transparency of mutual relatedness among senses and derivational paths of individual senses.

The question that has remained unanswered so far refers to sense ordering within a dictionary entry. The senses belonging to the same hierarchical layer or derivational level are, as the figure 2 shows, equally distant from the prototype so that their order cannot be established on the basis of the declining scale of their closeness to the prototype or 'from center to periphery' (Halas 2013: 276). Hence, the only logical criterion for ordering of senses on the same hierarchical layer is the frequency of their occurrence in the contemporary language use. Moreover, an insight into the frequency of various senses of a word is of great value to dictionary users. The frequency of a particular sense can be determined by analyzing a corpus of the contemporary language use. Senses on the same hierarchical layer are ordered according to the descending scale of their frequency in the contemporary language use. This principle is applied to every hierarchical layer in a structure. However, it should be noticed that only the prototypical sense is always listed first in an entry regardless of its frequency in the corpus in order to give it its due prominence.

\section{Illustration of the proposed model}

The application of the proposed model is illustrated by tailoring a dictionary entry for the verb drop:

drop verb /BrE drop, AmE dra:p/ drops, dropping, dropped

1. FALL ${ }^{2}[\mathrm{I}]$ to fall vertically:

[drop+adverb/preposition: from, onto, into...] The cup suddenly dropped from her hand. ${ }^{3}$ I noticed the moment when her earring dropped onto the green floor.

2. MAKE STH FALL [T] to make something fall vertically: She dropped her bag as soon as she entered the room.

a. DELIBERATELY $[\mathrm{T}]$ to deliberately make something fall vertically:

[drop something+adverb/preposition: from, onto, into...] I dropped the noodles into the water and gave them a stir. He and his son were dropping stones from the bridge into the river. 
a.1. BODY $[\mathrm{T} / \mathrm{I}]$ to deliberately make a part of your body fall suddenly:

She immediately dropped her head against the pillow. When she saw me, her mouth dropped/jaw dropped $^{4}$ (= she was very surprised). FORMAL When she asked him to tell her the truth, he just dropped his eyes (= looked downwards).

a.2. FROM AN AIRCRAFT [T] to deliberately make supplies, equipment or troops fall from an aircraft by parachute:

The ally dropped food supplies in the refugee camp.

a.3. WRITE A LETTER [T] to write or send a letter (which resembles deliberately making letters fall to the paper):

Just drop me a line/note from time to time.

a.4. UTTER $[\mathrm{T}]$ to say something informally or indirectly (which resembles deliberately making words fall from the mouth):

Mary dropped a hint that she would move to England the following year.

a.5. HIT A BALL [T] SPORT to make a ball fall into a hole, basket or goal:

You can drop a putt into the hole easily if the speed is good.

a.6. TAKE A DRUG [T] INFORMAL to take a drug by making it fall down your throat:

They knew that she dropped acid a couple of times.

b. ACCIDENTALLY $[\mathrm{T}]$ to accidentally make something fall vertically:

She dropped her favourite plate while doing the washing-up. I dropped the needle on the carpet and now I can't find it.

c. STOP DOING STH [T] to stop doing something (which resembles making an object fall to the ground):

Can you drop everything for a moment and give me a hand?

c.1. TALKING [T] to stop talking about something or discussing it:

Can you just drop it? I don't want to listen about it any more. After an hour of discussion, they finally dropped the subject.

c.2. RELATIONSHIP [T] INFORMAL to stop having a relationship with someone, especially a romantic one:

[drop somebody] After ten years, she dropped Tom. 
c.3. SCHOOL SUBJECT [T] to stop studying a school subject:

In her third year, Mary dropped German and chose another language.

c.4. COURT CASE $[\mathrm{T}]$ to stop dealing with a court case: The prosecution decided to drop the case.

d. LEAVE SB/STH OUT [T] to leave somebody or something out accidentally or deliberately (which resembles making an object fall to the ground):

[drop somebody/something from something] The editor asked them to drop that word from the title. The topic considered controversial was dropped from the list of the offered ones.

d.1. FROM A TEAM [T] SPORT to leave somebody out from a team or side:

[drop somebody from something] Thomson had a bad season so the coach dropped him from the team.

d.2. SOUND/LETTER $[T]$ to leave out a sound or a letter while pronouncing or writing a word:

He always drops his aitches when speaking in front of the audience. You dropped one 'r' every time you wrote 'tomorrow'.

e. LOSE STH $[\mathrm{T}]$ to fail to win something (which resembles making an object fall to the ground):

e.1. POINT/MATCH [T] SPORT to lose a point, match or competition:

The Blues drop points as Manchester City go top of the table. He won the tournament without dropping a single match.

e.2. MONEY [T] INFORMAL to lose or spend a particular amount of money, especially in gambling:

I dropped a thousand dollars in the casino last night. She dropped 50 euros for a portion of lobster.

f. UNLOAD [T] to leave passengers or goods at a particular place (which resembles making them fall to the place):

f.1. LEAVE SB SOMEWHERE [T] to take somebody by car and leave them at a particular place, especially on the way to another place:

Just drop me near the post office and I'll go by bus from there. I'm driving to work so I can drop you in the town centre.

f.2. LEAVE STH SOMEWHERE [T] to take something and leave it at a particular place without staying there very long: 
[drop something round/off] I found your wallet so I'll drop it round to your place when I finish my work. Just drop it off on your way home.

g. GIVE BIRTH TO [T] (of an animal) to give birth to young, especially a foal (which resembles making an object fall to the ground):

We are expecting a mare to drop a foal in a few days.

3. BECOME WEAKER/LESS/LOWER $[\mathrm{I}, \mathrm{T}]$ to become or make something reduced to a lower level, rate, number, intensity etc. (which resembles falling or making something fall vertically):

He suddenly dropped his voice when he realized that the baby was sleeping. [drop off] The production dropped off during last year. The temperature dropped sharply/dramatically/suddenly over last few days. The wind finally dropped on Sunday so we could continue our journey. [drop to] The price of shares dropped to 1,000 \$. Flats dropped in price by $15 \%$. You need to drop your speed when it is raining.

4. FALL IN DROPS $[\mathrm{I} / \mathrm{T}]$ to fall or make something fall vertically in drops of liquid:

The rain was dropping on the roof. Can you drop it into my eye?

5. COLLAPSE $[\mathrm{I}]$ to fall vertically to the ground unexpectedly or suddenly, as from a shot, wound, exhaustion, death, etc: [drop down, onto, into...] INFORMAL I was working so hard that at the end of the day I was ready to drop. We heard a shot and saw him dropping to his knees in the mud. When she came back, she just dropped into her favourite armchair feeling completely exhausted.

6. SLOPE DOWNWARDS [I] (of a ground) to slope steeply (as if falling vertically):

[drop away, down] It was a wonderful view - the land dropped away to the river. The path dropped down sharply.

a. SLIP INTO A STATE $[\mathrm{I}]$ to enter or pass into a particular state or condition without conscious effort (resembling a ground sloping steeply):

[drop into] He can ordinarily drop into sleep at times when he should be occupied.

\section{Conclusion}

The concluding remarks of this paper will concisely point out the benefits of 
the proposed model for both lexicographers and dictionary users. Namely,

(a) The proposed model of lexicographic treatment of polysemy has a solid theoretical foundation built on the principles of a contemporary lexicological theory (the prototype theory).

(b) The proposed model reliably reflects the nature of a polysemous structure including its hierarchical organization, mutual relatedness of senses based on family resemblance and motivated derivation of senses, making all these prominent features of a polysemous structure fully transparent.

(c) Consequently, this model of polysemy treatment can be justifiably expected to achieve practical efficiency that refers to proper and complete fulfilment of users' needs including, primarily, quick detection of a particular sense and its memorization and comprehension with less effort. Also, this model can satisfactorily meet research and scholarly needs of dictionary users.

(d) In addition, the visual representation of an entry is consistent, systematic, clear and precise, which significantly contributes to the previously mentioned practical efficiency of the model.

(e) In conclusion, the proposed model is characterized by solid scientific foundation, consistency, systematicity and uniformity, which is expected to lead to considerable reduction of arbitrariness in the treatment of polysemy in dictionaries.

The idea underpinning the proposed model is that the prototype theory offers a firm basis for defining a set of strategies that will successfully tackle some of the most challenging lexicographic issues, such as the treatment of polysemy. Actually, the proposed model represents an illustration of the premise that such a firm theoretical basis ensures enhanced efficiency of lexicographic practice.

\section{Endnotes}

1. For the purpose of illustrating the proposed model of polysemy treatment, the sense network of the verb drop has been created on the basis of a sense inventory compiled after the excerption of all various senses offered within entries for this verb in various monolingual dictionaries of English, including general-purpose and learner's dictionaries.

2. The proposed model involves the use of sense indicators in front of definitions, which is considered as good practice already adopted by certain learner's dictionaries of English (Oxford Advanced Learner's Dictionary, Longman Dictionary of Contemporary English, Cambridge Advanced Learner's Dictionary) and for example, Encarta World English Dictionary as a generalpurpose dictionary of English. A sense indicator is a word or a short phrase expressing the most prominent or specific component of the given sense. Such practice enables quick and easy search of an entry. 
3. For this particular purpose of tailoring a single example entry to illustrate the proposed model, example sentences have been formulated by the author of the paper herself as her attempt to provide illustrations of the typical context in which each sense is used.

4. Lexical collocations provided in illustrative examples are marked by red colour.

\section{References}

Atkins, B.T.S. and M. Rundell. 2008. The Oxford Guide to Practical Lexicography. Oxford/New York: Oxford University Press.

Brugman, C. and G. Lakoff. 1988. Cognitive Topology and Lexical Networks. Small, S., G. Cottrell and M. Tannenhaus (Eds.). 1988. Lexical Ambiguity Resolution: 477-507. San Mateo: Morgan Kaufman.

Croft, W. and D.A. Cruse. 2004. Cognitive Linguistics. Cambridge: Cambridge University Press.

Cruse, A. 2004. Meaning in Language. An Introduction to Semantics and Pragmatics. Second Edition. Oxford: Oxford University Press.

Csábi, S. 2002. Polysemous Words, Idioms and Conceptual Metaphors. Cognitive Linguistics and Lexicography. Braasch, A. and C. Povlsen (Eds.). 2002. Proceedings of the Tenth EURALEX International Congress, EURALEX 2002, Copenhagen, Denmark, 13-17 August 2002: 249-254. Copenhagen: Center for Sprogteknologi, University of Copenhagen.

Evans, V. 2005. The Meaning of Time: Polysemy, the Lexicon and Conceptual Structure. Journal of Linguistics 41(01): 33-75.

Evans, V. and M. Green. 2006. Cognitive Linguistics: An Introduction. Edinburgh: Edinburgh University Press.

Geeraerts, D. 1989. Prospects and Problems of Prototype Theory. Linguistics 27: 587-612.

Geeraerts, D. 2001. The Definitional Practice of Dictionaries and the Cognitive Semantic Conception of Polysemy. Lexicographica 17: 6-21.

Halas, A. 2013. The Representation of a Multidimensional Semantic Structure in English Monolingual Learner's Dictionaries. Gudurić, S. and M. Stefanović (Eds.). 2013. Languages and Cultures in Time and Space II: 269-280. Novi Sad: Faculty of Philosophy.

Halas, A. 2014a. Polysemy in Dictionaries of English and Serbian: Theoretical, Methodological and Practical Aspects of its Treatment. An unpublished doctoral dissertation. Novi Sad: University of Novi Sad.

Halas, A. 2014b. The Treatment of Polysemy in the Oxford Dictionary of English. Prćić, T. et al. (Eds.). 2014. Festschrift in Honour of Draginja Pervaz English Language and Anglophone Literatures in Theory and Practice: 155-172. Novi Sad: Faculty of Philosophy.

Jackson, H. 2002. Lexicography. An Introduction. London/New York: Routledge.

Jehle, G. 2004. Prototype Semantics and Learners' Dictionaries of English. Herbst, T. et al. (Eds.). 2004. Lexikografie, ihre Basis- und Nachbarwissenschaften: 53-69. Tübingen: Max Niemeyer.

Lakoff, G. 1987. Women, Fire, and Dangerous Things. What Categories Reveal about the Mind. Chicago: University of Chicago Press.

Lewandowska-Tomaszczyk, B. 2007. Polysemy, Prototypes, and Radial Categories. Geeraerts, D. and H. Cuyckens (Eds.). 2007. The Oxford Handbook of Cognitive Linguistics: 139-169. Oxford: Oxford University Press. 
http://lexikos.journals.ac.za

Pearsall, J. (Ed.). 1998. The New Oxford Dictionary of English. Oxford: Oxford University Press.

Prćić, T. 2016. Semantika i pragmatika reči. Third electronic edition. Novi Sad: Faculty of Philosophy.

Ravin, Y. and C. Leacock (Eds.). 2006. Polysemy. Theoretical and Computational Approaches. Oxford: Oxford University Press.

Rosch, E. 1977. Human Categorization. Warren, N. (Ed.). 1977. Advances in Cross-Cultural Psychology. Volume 1: 1-72. London: Academic Press.

Stock, P.F. 1984. Polysemy. Hartmann, R.R.K. (Ed.). 1984. LEXeter' 83 Proceedings. Papers from the International Conference on Lexicography, Exeter, 9-12 September 1983. Lexicographica. Series Maior 1: 131-141. Tübingen: Max Niemeyer.

Svensén, B. 2009. A Handbook of Lexicography. The Theory and Practice of Dictionary-Making. Cambridge: Cambridge University Press.

Taylor, J.R. 1989. Linguistic Categorization. Prototypes in Linguistic Theory. Oxford: Clarendon Press.

Van der Meer, G. 2000. Core, Subsense and the New Oxford Dictionary of English (NODE). On How Meanings Hang Together, and not Separately. Heid, U. et al. (Eds.). 2000. Proceedings of the Ninth EURALEX International Congress, EURALEX 2000, Stuttgart, Germany, 8-12 August 2000: 419-431. Stuttgart: Institut für Maschinelle Sprachverarbeitung, University of Stuttgart.

Wittgenstein, L. 1980. Philosophische Untersuchungen. Frankfurt am Mein: Suhrkamp. 